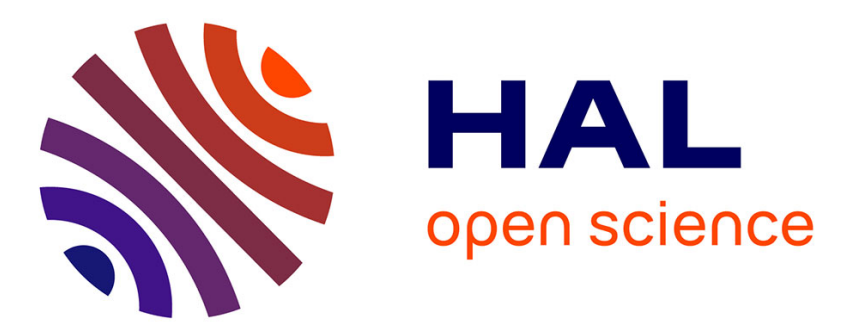

\title{
Derivation of simplified control rules from an optimal strategy for electrical heating in a residential building
}

M. Robillart, P. Schalbart, Bruno Peuportier

\section{To cite this version:}

M. Robillart, P. Schalbart, Bruno Peuportier. Derivation of simplified control rules from an optimal strategy for electrical heating in a residential building. Journal of Building Performance Simulation, 2017, 11 (3), pp.294-308. 10.1080/19401493.2017.1349835 . hal-01982624

\section{HAL Id: hal-01982624 \\ https://hal.science/hal-01982624}

Submitted on 12 Feb 2019

HAL is a multi-disciplinary open access archive for the deposit and dissemination of scientific research documents, whether they are published or not. The documents may come from teaching and research institutions in France or abroad, or from public or private research centers.
L'archive ouverte pluridisciplinaire HAL, est destinée au dépôt et à la diffusion de documents scientifiques de niveau recherche, publiés ou non, émanant des établissements d'enseignement et de recherche français ou étrangers, des laboratoires publics ou privés. 


\title{
Derivation of simplified control rules from an optimal strategy for electric heating in a residential building
}

\author{
M. Robillart ${ }^{1}$, P. Schalbart ${ }^{1}$, B. Peuportier ${ }^{1}$ \\ ${ }^{(1)}$ MINES ParisTech, PSL Research University, CES - Centre for energy efficiency of \\ systems, 60 Bd St Michel 75006 Paris, France \\ E-mail addresses: maxime.robillart@mines-paristech.fr (M. Robillart), \\ patrick.schalbart@mines-paristech.fr(P.Schalbart),bruno.peuportier@mines- \\ paristech.fr (B. Peuportier)
}

In France, $40 \%$ of buildings are heated with electrical devices causing high peak load in winter. In this context, advanced control systems could improve buildings energy management. More specifically, optimal strategies have been developed using a dynamic programming method in order to shift heating load, taking advantage of the building thermal mass. However, this optimisation method is computationally intensive and can hardly be applied to real-time control. Statistical techniques can be used to derive near-optimal laws from the optimal control results. These rule extraction techniques model the relationship between explanatory variables and a response variable. This paper investigates the use of Beta regression model. This regression-based strategy was able to mimic the general characteristics of the optimisation results with a small mean bias error ($6 \%$ ) and greatly reduce computational effort (150 times faster). Given its simple mathematical formulation, it could be implemented in real-time building systems control.

Keywords: rule extraction, offline optimisation, dynamic programming, load shifting, Beta regression

\section{Introduction}

High insulation levels make new energy efficient buildings increasingly sensitive to variations of solar and internal gains, which induce new challenges for the development of advanced control algorithms. In this context, the main objectives of the developed control systems are to save energy (Nygard Ferguson 1990), to increase 
comfort (Mathews et al. 2000), and to reduce peak electricity demand (Greensfelder et al. 2011). To meet such objectives, control systems have to anticipate future weather, occupancy, solar and internal gains.

The building sector is an important consumer of electricity and producer of greenhouse gases emissions. In France, it accounts for $68 \%$ of the final electricity consumption and represents a key component of peak electricity demand during winter periods as $40 \%$ of buildings are heated with electrical devices (ADEME 2012). Recently, with the development of communication technologies and smart grids, numerous efforts have been made to reduce electricity peak demand. Especially, some studies focused on electrical load shifting to guarantee grid stability. Thanks to electricity demand response (DR), the consumer demand for energy can be modified through various methods such as financial incentives or information. Advanced control systems can be used to reduce peak electricity demand. Such control may be driven by power tariff (Hämäläinen et al. 2000; Pineau and Hämäläinen 2000). In order to maintain satisfactory temperatures, the control could take advantage of the thermal mass of the building to shift electricity consumption from peak to off-peak hours (Kelly et al. 2011; Wyse 2011). For instance in the latter case, Favre and Peuportier (2014) showed that it was possible to shift the load of heating to off-peak hours in the case of a highly insulated building with high thermal mass. They used the dynamic programming method to study the control of the heating system. The control strategy calculated by the optimisation algorithm consisted in over-heating the building in the hours before the peak based on seven days forecast of weather, occupancy, and internal gains.

To meet such objectives and the growing demand for better control of energy efficient buildings, it is necessary to develop new advanced control techniques accessible to building designers and operators. In this context, Model Predictive Control (MPC) is 
promising for energy efficient control in building. The principle of MPC is to repeatedly solve a finite-horizon optimal control problem. At each controller time step (set by the user), a building model and optimisation algorithm are used to calculate the optimal sequence of control (the optimal trajectory that emerges from the current state of the building) over a prediction horizon. Usually, only the first time step of the solution is applied, and a new optimisation occurs at the next controller time step with updated state and disturbances prediction (receding control horizon). Variants of this configuration are possible, such as implementing several time steps of the solution. Recently, a great deal of scientific work on the use of MPC in buildings has been carried out (Henze et al. 2005; Freire et al. 2008; Moroşan et al. 2010; Oldewurtel et al. 2012; Corbin et al. 2013; Touretzky and Baldea 2014). Its major benefits are its ability to handle constraints, to anticipate the future behaviour of the building and consequently to respond to a wide range of building control applications. For example, MPC is most effective when thermal energy storage (passive thermal mass or active systems) is available. Furthermore, the advances in building automation and computing power enable an increase in the number of buildings that can potentially benefit from MPC application. However, the major challenge of this approach is its implementation in most building automation systems. MPC requires a more complex IT infrastructure (hardware and software) and commission engineers trained to set up complex control systems based on numerical optimisation methods.

Consequently, recent work has considered offline optimisation methods to approximate the exact optimisation results (or MPC results) and then to deduce a set of simple control rules (rule-based control, RBC). A first approach is to attempt to solve explicitly the optimal control problem. Coffey (2013) proposed a new methodology to approximate MPC with lookup tables (linear interpolation of MPC control laws) and 
methods to contain the problem dimensionality. A second approach is to simulate MPC offline assuming user profiles and typical weather data. Near-optimal control laws are extracted from the offline MPC results by means of statistical techniques. This approach was first applied in water resource management in order to develop simplified control rules for reservoir management based on the results of offline MPC (Wei and Hsu 2009). The approach has recently been applied to the building context. For instance, May-Ostendorp et al. (2013) used many data mining techniques (generalised linear models, classification and regression trees, and adaptive boosting) to extract rules from offline MPC results for a mixed mode building operated during the cooling season. Recently, some algorithms in the field of Machine Learning such as AdaBoost and Support Vector Machine (SVM) were used (Domahidi et al. 2014). For example, Le et al. (2014) developed a logical controller for shading systems based on the MPC results' behaviour learning using the SVM method. However, these studies have only focused on binary decisions or a limited number of decisions.

The present study aims at developing operational strategies to shift the heating load in building. A new methodology described in a previous paper (Robillart et al. 2014) was applied to extract decision models from the dynamic programming results obtained by Favre and Peuportier (2014). A beta regression technique was used to develop decision rules for continuous input on the basis of results from dynamic programming application, which has never been attempted in the context of MPC in buildings. Section 2 introduces the framework study in which the thermal model, the building description and optimisation parameters are presented. The methodology for decision model extraction from the dynamic programming results is detailed in section 3 . Finally, section 4 illustrates the simulation results of the identified operational strategies. 


\section{Framework study}

\subsection{Thermal model of the building}

The dynamic building energy software COMFIE, developed by Peuportier and Blanc-Sommereux (1990) was used in this study. This model relies on the concept of thermal zone which is a section of the building (generally comprising one or more rooms) with a homogeneous temperature. The main modelling steps implemented in this tool are the meshing of the building envelope (using a finite volume technique), the set-up of a continuous and linear time-invariant system for each thermal zone, the reduction of the model by modal analysis, and finally the coupling between the thermal zones. The model simulation requires specifying driving forces. In particular, the occupancy schedule of the building which defines the heat generation by the inhabitants and appliances, and the thermostat setpoint influencing the heating equipment, must be specified, as well as the meteorological data influencing heat losses and solar gains. Phenomena that are non-linear or involving variable parameters (ventilation, thermal resistance added due to intermittent use of shutters, etc.) are taken into account through additional driving forces. On top of several validation studies (Peuportier 2005), the model's reliability was studied in the particular context of a high performance house and is equivalent to international reference models (Brun et al. 2009, Munaretto et al. 2013, Recht et al. 2014).

\subsection{Building description}

The building considered in this study is a single family house representative of a new construction in France. It corresponds to an experimental house being part of the "INCAS" platform built in Le Bourget du Lac, France, by the National Solar Energy Institute (INES), except regarding air tightness. Instead of a very low infiltration according to the passive house label, an air flowrate of 0.6 air change per hour $(\mathrm{ACH})$ is 
considered, corresponding to a low energy consumption performance like in the French regulation.

The building has two floors with a total living area of $89 \mathrm{~m}^{2}$ (Figure 1). The north facade has only two small triple glazing windows $\left(U_{g w}=0.7 \mathrm{~W} \cdot \mathrm{m}^{-2} \cdot \mathrm{K}^{-1}\right.$, $S F=0.45$ ) whereas $28 \%$ of the south facade is covered by double glazing windows $\left(U_{g w}=1.1 \mathrm{~W} \cdot \mathrm{m}^{-2} \cdot \mathrm{K}^{-1}, S F=0.6\right)$ of various dimensions. The south facade also includes solar protection for the summer period. The house is made of shuttered concrete (15 cm thick) with external insulation ( $20 \mathrm{~cm}$ of extruded polystyrene), a heavy ground floor ( $24 \mathrm{~cm}$ concrete slab and $20 \mathrm{~cm}$ external insulation), a heavy intermediate floor $(16 \mathrm{~cm}$ concrete screeds and girders and $12 \mathrm{~cm}$ overlaying concrete slab floor), and a lightweight ceiling (1 $\mathrm{cm}$ plasterboard and $40 \mathrm{~cm}$ of glass wool). Thermal bridges and air tightness are low thanks to a careful design and implementation.

The occupancy was simulated according to the stochastic model developed by Vorger et al. (2014). Based on multiple statistical data, e.g. French socio-demographic and timeuse survey but also measurement campaigns, the model generates realistic inhabitants' characteristics and behaviours through a probabilistic approach. A stochastic process sets users' characteristics and presence scenarios. The corresponding activities are generated and associated with the use of electrical appliances and lighting. From several hundred simulations of this model, it was possible to establish average occupancy scenarios via the resulting statistical distributions. These scenarios are more realistic than those defined by conventional ratios and profiles. In this study, average statistical scenarios for the occupancy were created for the experimental passive house with high performance appliances and lighting (we considered an occupancy of three people). Figure 2 presents the average internal gains scenario in the building during a week 
derived from a sample of 250 generated scenarios. A heat exchanger allowed heat recovery from exhaust air with a $90 \%$ efficiency. The house was heated by an electrical resistance and no air-conditioning system was installed. In this numerical study, we only focused on the electrical heating system (assuming a $100 \%$ efficiciency), which was modelled in the simulation platform COMFIE. The ventilation flowrate corresponded to a constant flowrate required to maintain adequate indoor air quality for three people; it was not controlled so that air pollutants (from furniture for instance) were always evacuated.

The model of the building was mono-zonal in order to reduce calculation time of the optimisation algorithm, to study the rule extraction feasibility and to simplify the control rules development.

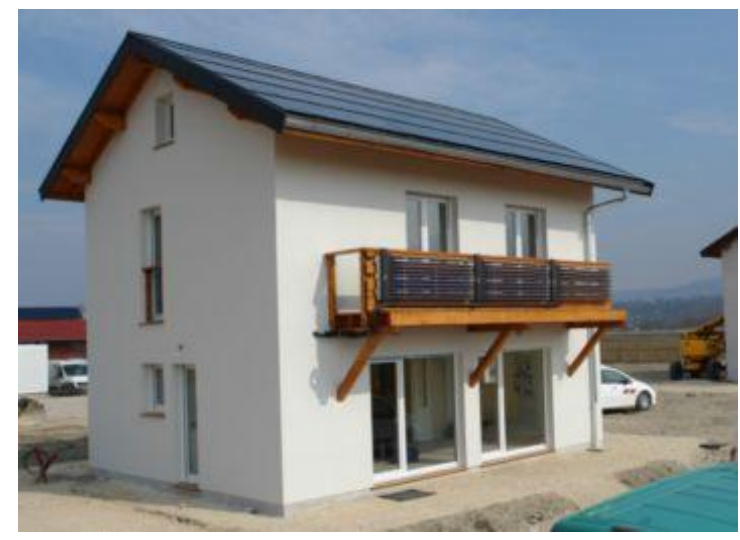

Figure 1. View of the house (west and south facades). 


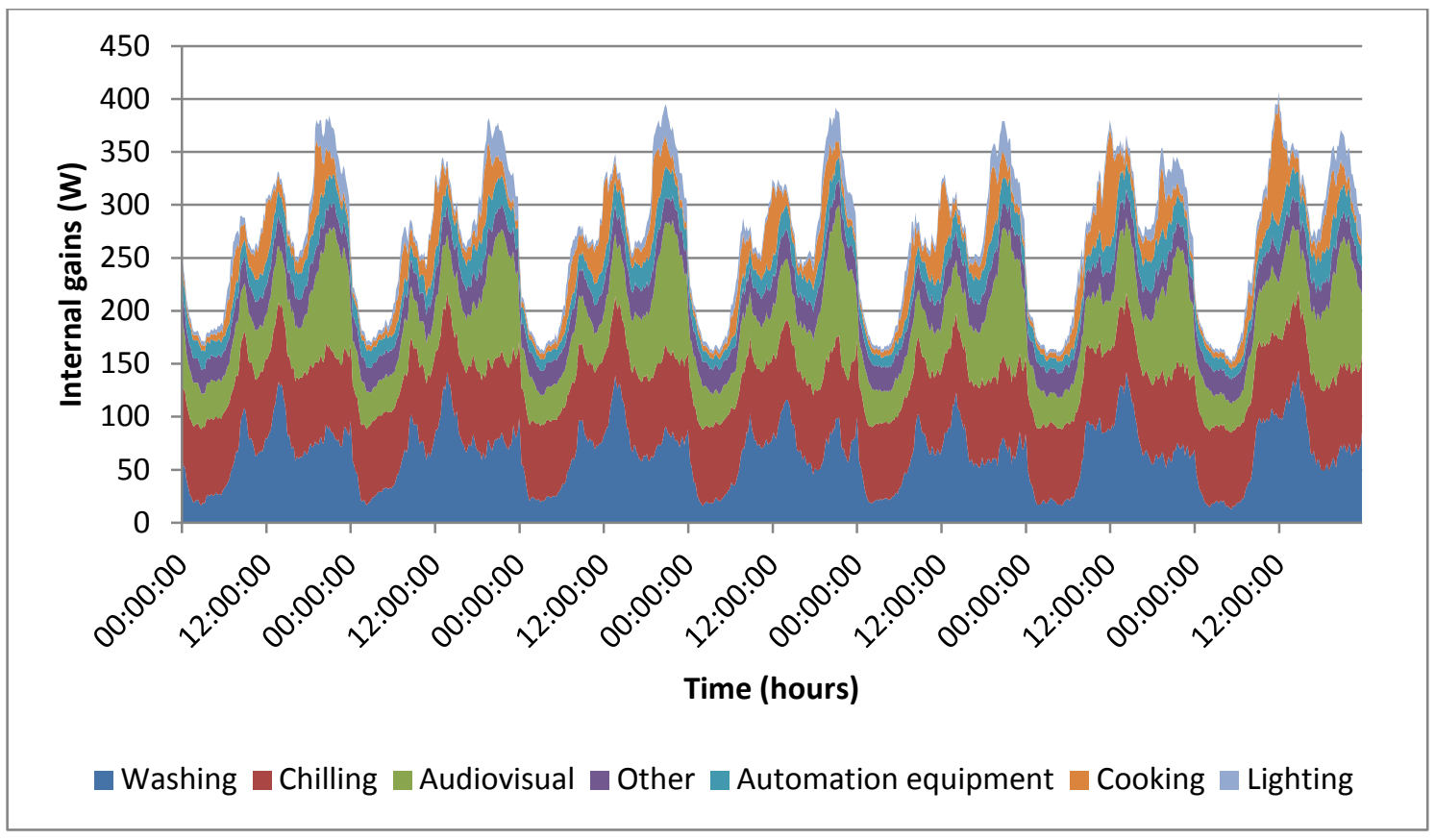

Figure 2. Generated average internal gains scenario in a dwelling occupied by three inhabitants.

\subsection{Optimisation problem}

A predictive controller, using the dynamic programming method, was investigated in order to shift heating loads from peak hours to off-peak hours. The goal of the optimisation was to minimise the heating cost by determining a set of commands (heating power $P$ ) with constraints on thermal comfort and heating power. To ensure thermal comfort, indoor temperature had to be maintained between $19^{\circ} \mathrm{C}\left(T_{\min }\right)$ and $24^{\circ} \mathrm{C}\left(T_{\max }\right)$. The heating power could vary between $0 \mathrm{~W}\left(P_{\min }\right)$ and $5000 \mathrm{~W}\left(P_{\max }\right)$. Thus, the finite-horizon decision problem took the following form:

$$
\min _{P} \sum_{0}^{t f} C_{\text {elec }}(t) P(t) \Delta t
$$

with

- $C_{\text {elec }}$ the dynamic electricity cost,

- $\quad P$ the heating power, 
- $\Delta t$ the time step,

- $t f$ the duration of the optimisation period.

and with state and control constraints:

$$
\begin{gathered}
T_{\min } \leq T_{\text {zone }}(t) \leq T_{\max } \\
P_{\min } \leq P(t) \leq P_{\max }
\end{gathered}
$$

We considered also a maximal rate of variation constraint for the zone temperature (ASHRAE 2004):

$$
\frac{d T_{\text {zone }}}{d t} \leq 2.2^{\circ} \mathrm{C} / \mathrm{h}
$$

To shift the electricity demand, Time-of-Use (TOU) rates were used, adapted from the current prices in France by adding high peak hour rates (Table 1).

Table 1. Electricity prices.

\begin{tabular}{|c|c|c|c|}
\hline & Off-peak hours & Peak hours & High peak hours \\
\hline Hours & 12 a.m. to 9 a.m. & 9 a.m. to 5 p.m. & 5 p.m. to 10 p.m. \\
& & 10 p.m. to 12 a.m. & \\
\hline Cost per kWh $(€)$ & 0.0864 & 0.1275 & 0.255 \\
\hline
\end{tabular}

\section{Methodology}

\subsection{Optimisation algorithm}

The dynamic programming method was developed by Bellman (1957). It is a sequential optimisation method which examines all possible control paths to solve an optimisation problem and provides an optimal set of commands over a period. More precisely, the dynamic programming method breaks the decision problem into smaller 
sub-problems using Bellman's Principle of Optimality: “An optimal policy has the property that whatever the initial state and initial decision are, the remaining decisions must constitute an optimal policy with regard to the state resulting from the first decision". Achievement of a global optimum is guaranteed using this method to the sequential decision-making problem. To apply this optimisation algorithm, a state variable describing the system is used and discretised temporally.

In this study, decision models were extracted from dynamic programming results obtained by Favre and Peuportier (2014). They applied the optimisation algorithm to solve the finite-horizon decision problem (1) in which the chosen state variable was the total energy stored in the building. This optimisation algorithm was directly implemented within the simulation platform COMFIE. Further details on the dynamic programming predictive controller are provided in Favre and Peuportier (2014).

\subsection{Rule extraction}

Rule extraction techniques were used to derive simplified control rules from the dynamic programming results (offline optimisation). These control rules calculate the heating power (response variable) according to some explanatory variables (e.g. indoor temperature, outside temperature, etc.). The rule extraction methodology can be summarised in a three-step process. Firstly, the COMFIE model and the dynamic programming method integrated into COMFIE were used to generate training and validation data (corresponding to the optimal heating control strategy). Secondly, training data were used to extract heating control rules. Thirdly, theses control rules were implemented back in the COMFIE model to assess the reliability of the identified heating control rules.

The following subsections describe the techniques for logistic decision models 
extraction from the offline optimisation and assessment of the reliability of the identified heating control rules.

\subsubsection{Beta regression}

Regression analysis estimates the expected value of a response variable $y$ given regressors $x_{j}$ (explanatory variables). In this way, some regression models can be used to describe the relationship between explanatory variables (indoor temperature, weather conditions, electricity tariff, etc.) and a response variable (the heating power $P$ calculated by the dynamic programming method). For a response variable with a lower and upper bound (e.g. the heating power $P$ constrained between $P_{\min }$ and $P_{\max }$,), a suitable candidate is the Beta regression, which is very flexible. In particular, the class of Beta regression models is useful for problems in which the response variable is continuous and restricted to the open unit interval $] 0,1[$, and is related to explanatory variables through a regression structure.

Ferrari and Cribari-Neto (2004) proposed a regression model based on the assumption that the response variable is Beta-distributed and that its mean is related to explanatory variables through a linear predictor with unknown coefficients and a link function. This Beta regression model is based on an alternative parameterisation of the Beta distribution.

Let $P_{1}, \ldots P_{n}$ be some observations at different time steps of the heating power $P$ calculated by the dynamic programming method. The Beta regression model was used to relate $P$ to explanatory variables (regressors) $x_{j}$ through a link function $g$ :

$$
g\left(P_{i}\right)=b_{0}+b_{1} x_{i, 1}+\cdots+b_{p} x_{i, p}
$$

where 
- $i=1, \ldots, n$ the observations number,

- $P_{i}$ the $i^{\text {th }}$ observation of the response variable $P$,

- $x_{i, j}$ the $i^{\text {th }}$ observation of the $j^{\text {th }}$ explanatory variable,

- $b_{j}(j=0, \ldots, p)$, the $(p+1)$ regression parameters estimated by maximum likelihood,

- $g($.$) the link function which is strictly increasing and twice differentiable.$

The Beta regression parameters are estimated using the maximum likelihood method. In this study, we used a stepwise regression technique in which the choice of the retained explanatory variables is carried out by backward elimination (Wilks 1995). More precisely, explanatory variables which are not statistically significant are deleted from the Beta regression model until all the explanatory variables remaining are statistically significant.

Some useful link functions can be used as the logit function $\left(g(P)=\log \left(\frac{P}{1-P}\right)\right)$ or probit function $\left(g(P)=\Phi^{-1}(P)\right.$, where $\Phi$ is the standard normal distribution function). In this study, the logit function, which is commonly employed, was used. As the response variable $P$ varied between $P_{\min }$ and $P_{\max }$, it was transformed from its original scale to the unit interval $[0,1]$ by defining:

$$
P^{\prime}=\left(P-P_{\min }\right) /\left(P_{\max }-P_{\min }\right)
$$

Furthermore, as the response variable takes values in the standard unit interval ]0,1[, a useful transformation in practice was used: $P^{\prime \prime}=\left(P^{\prime}(n-1)+0,5\right) / n$, where $n$ is the sample size (Smithson and Verkuilen 2006, Schmid et al. 2013). Further details on the Beta regression model and the alternative parameterisation of the Beta distribution are provided in Ferrari and Cribari-Neto (2004). 


\subsubsection{Rule extraction methodology}

The COMFIE model and the dynamic programming method were used to generate training and validation data to identify Beta regression parameters and to assess the reliability of the identified Beta strategies respectively.

Typical Meteorological Year (TMY) weather data were used to perform optimisation using dynamic programming and to calculate the optimal strategy (training data). A TMY is a composite of selected weather data for a specific location, and represents the typical long-term average weather. More precisely, continuous hourly weather data are collected over several years and a TMY file is constructed by concatenation of representative weather periods. General heating control strategies adapted to long-term average climatic conditions of the location require TMY weather data. Approximately two-thirds of the optimised results (training data) were used to identify the Beta regression parameters and thus to determine simplified heating control rules. The reliability of the identified Beta strategies (heating control rules) was assessed using the remaining third of the optimised results and closed-loop simulation. Closed loop tests depict more realistically the actual performance of the identified heating control rules. In this case, the rule was implemented within a building energy model and predicted the current time step action using state information from the previous time step of the simulation. Consequently, actions determined by the strategy directly impacted the thermal state of the building and thus the next iteration of the rule. The heating control rules were embedded in the building energy model COMFIE and predicted the heating Power $P$ at time $t+\Delta t$ (where $\Delta t$ is the time step, one hour in this case study).

The identification and validation process is depicted in Figure 3. Firstly, all data used by the dynamic programming were collected (TMY weather data, electricity tariff, occupancy). Secondly, the optimal strategy was calculated by the dynamic 
programming method, and optimised results were divided into training and validation data. Thirdly, Beta regression parameters were identified thanks to the training data. Several strategies were designing from different training data sets (see $§ 3.2 .3$ below). Fourthly, the resulting simplified control Beta strategies (identified heating control rules) were implemented within the simulation platform COMFIE. Finally, the closedloop performances of operational strategies were compared with the validation data.

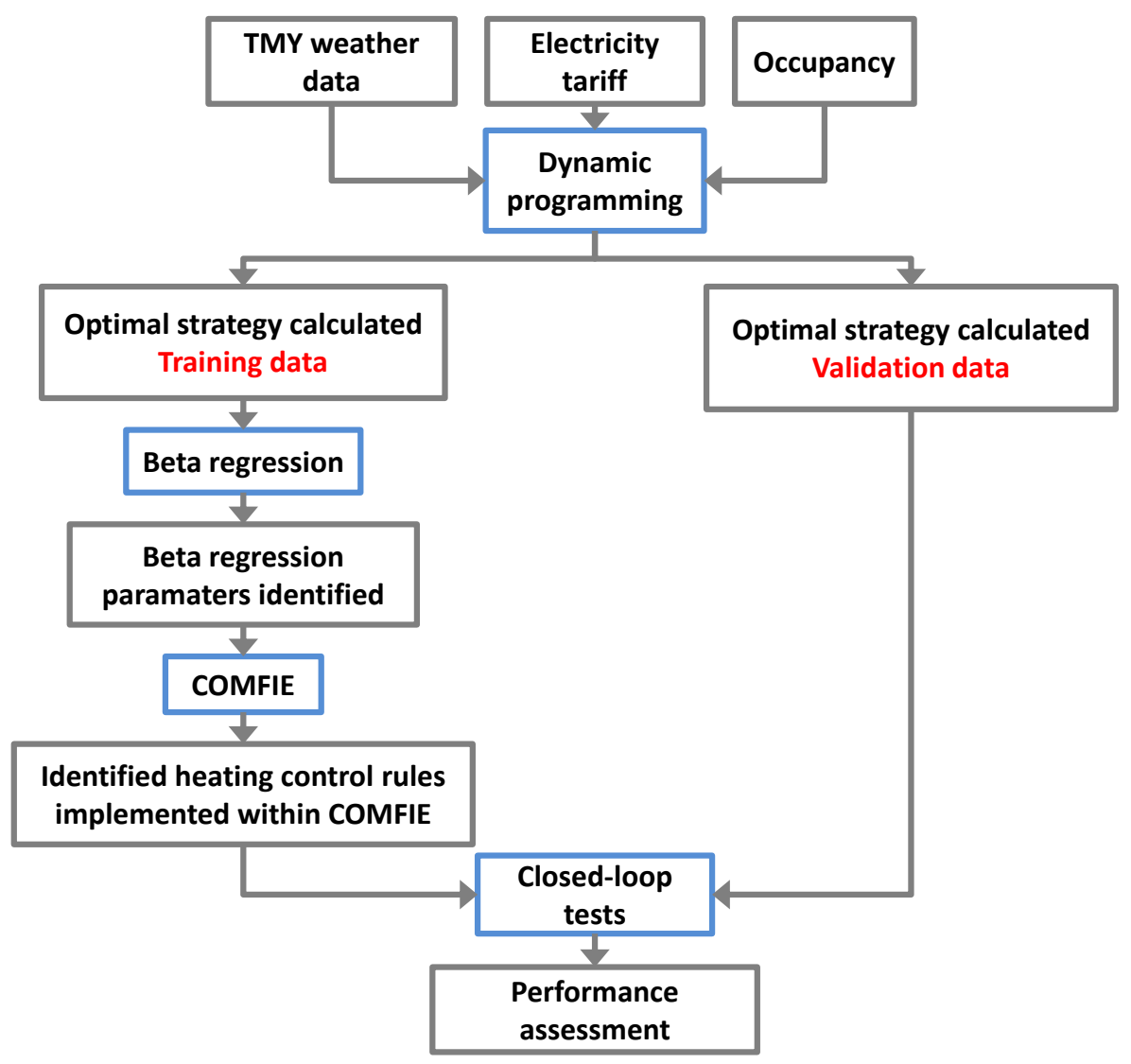

Figure 3. Heuristic model identification and validation.

\subsubsection{Developed Beta strategies}

Beta strategies development can be summarised in a three-step process. Firstly, different preliminary Beta strategies were identified based on the results of the dynamic programming algorithm and different sets of training data. Each Beta strategy was identified using all or some of the training data, divided into three sets: off-peak hours 
training data $\left(T D_{O P H}\right)$, peak hours training data $\left(T D_{P H}\right)$, and high peak hours training data $\left(T D_{H P H}\right)$. For instance, the preliminary Beta strategies BETA_1, BETA_4 and BETA_5 were based on the entire training data set, while the preliminary Beta strategies BETA_2 and BETA_3 used only a portion of it (see Table 2).

Secondly, to ensure load shifting during peak hours and high peak hours, these preliminary Beta strategies were then adjusted to impose zero heating output during certain periods. Thus, the heating power initially predicted by the $i^{\text {th }}$ Beta strategy (noted $P_{B E T A_{-} i}$ ) was voluntary set at $0 \mathrm{~W}$ in the following cases (Table 3):

- during high peak hours for BETA_2, BETA_3, BETA_4 and BETA_5 strategies,

- during peak hours for BETA_3 and BETA_5 strategies.

Thirdly, the adjusted Beta strategies were then implemented in the dynamic building energy simulation tool COMFIE, and the results were compared with the performance of the dynamic programming algorithm.

Table 2. Training data.

\begin{tabular}{|c|c|c|c|}
\hline & \multicolumn{3}{|c|}{ Training data } \\
\hline & Off-peak hours & Peak hours & High peak hours \\
\hline BETA_1 & $T D_{O P H}$ & $T D_{P H}$ & $T D_{H P H}$ \\
\hline BETA_2 & $T D_{O P H}$ & $T D_{P H}$ & - \\
\hline BETA_3 & $T D_{O P H}$ & - & - \\
\hline BETA_4 & $T D_{O P H}$ & $T D_{P H}$ & $T D_{H P H}$ \\
\hline BETA_5 & $T D_{O P H}$ & $T D_{P H}$ & $T D_{H P H}$ \\
\hline
\end{tabular}


Table 3. Implementation of Beta strategies.

\begin{tabular}{|c|c|c|c|}
\hline & \multicolumn{3}{|c|}{ Heating power } \\
\hline & Off-peak hours & Peak hours & High peak hours \\
\hline BETA_1 & $P_{\text {BETA_1 }}$ & $P_{B E T A_{-} 1}$ & $P_{\text {BETA_1 }}$ \\
\hline BETA_2 & $P_{B E T A \_2}$ & $P_{B E T A \_2}$ & $P_{B E T A_{\_} 2}=0$ \\
\hline BETA_3 & $P_{B E T A \_3}$ & $P_{\text {BETA_3 }}=0$ & $P_{B E T A_{-} 3}=0$ \\
\hline BETA_4 & $P_{\text {BETA_4 }}$ & $P_{B E T A_{-} 4}$ & $P_{B E T A_{-} 4}=0$ \\
\hline BETA_5 & $P_{B E T A \_5}$ & $P_{\text {BETA_5 }}=0$ & $P_{B E T A_{-} 5}=0$ \\
\hline
\end{tabular}

Thus, BETA_3 and BETA_5 strategies were different because they did not have the same training data. BETA_3 was trained only on off-peak hours training data $\left(T D_{O P H}\right)$ whereas BETA_5 was trained on complete training data $\left(T D_{O P H}, T D_{P H}, T D_{H P H}\right)$. However, in the implementation, the heating power at time $t+\Delta t$ was set at $0 \mathrm{~W}$ during high peak hours and peak hours for both strategies. The same logic was applied for BETA_2 and BETA_4 strategies. Concerning BETA_1 and BETA_5 strategies, the complete training data were used to identify both strategies but the heating power predicted by the Beta strategy was set at $0 \mathrm{~W}$ (during high peak hours and peak hours) for the BETA_5 strategy case.

\subsubsection{Explanatory variables}

The goal of the five Beta strategies was to replicate the heating power strategy calculated using the dynamic programming method. Identifying Beta strategies required defining explanatory variables (or regressors) used in the Beta regression. We initially examined explanatory variables that can be easily measured in buildings. In order to capture process memory, time-lagged explanatory variables were considered. For example, we considered the current temperature, $\mathrm{T}_{\text {zone }}(\mathrm{t})$, and temperature values 
during the previous hours $\left(\mathrm{T}_{\text {zone }}(\mathrm{t}-\Delta \mathrm{t}), \mathrm{T}_{\mathrm{zone}}(\mathrm{t}-3 \Delta \mathrm{t}), \mathrm{T}_{\mathrm{zone}}(\mathrm{t}-6 \Delta \mathrm{t})\right.$, etc. $)$ as regressors. Similarly, to anticipate weather and electricity tariff evolutions, explanatory variables predictions (e.g. $\mathrm{T}_{\text {out }}(\mathrm{t}+3 \Delta \mathrm{t})$ ) were considered. Finally, to introduce autoregressive characteristics into the model, the heating power used during the previous time steps (e.g. $\mathrm{P}(\mathrm{t}-6 \Delta \mathrm{t})$ ) was also included in the explanatory variables. A summary of the explanatory variables considered in this study is presented in Table 4 .

Table 4. Candidate explanatory variables (regressors).

\begin{tabular}{|c|l|l|}
\hline Variable & Description & Considered time step \\
\hline$T_{\text {out }}$ & Outdoor temperature & $t+\Delta t ; t+3 \Delta t ; t+6 \Delta t$ \\
\hline$G_{h}$ & Global horizontal radiation & $t+\Delta t ; t+3 \Delta t ; t+6 \Delta t$ \\
\hline$C_{\text {elec }}$ & Electricity tariff & $t+\Delta t ; t+3 \Delta t ; t+6 \Delta t$ \\
\hline$T_{\text {min }}$ & $\begin{array}{l}\text { Minimal acceptable temperature } \\
\text { in heating zones (thermal zones) }\end{array}$ & $t+\Delta t ; t+3 \Delta t ; t+6 \Delta t$ \\
\hline$T_{\text {zone }}$ & Indoor temperature & $\begin{array}{l}t ; t-\Delta t ; t-3 \Delta t ; t-6 \Delta t ; \\
t-12 \Delta t ; t-24 \Delta t\end{array}$ \\
\hline$H_{\text {gains }}$ & Internal heat gains & $\begin{array}{l}t+6 \Delta t ; t+3 \Delta t ; t+\Delta t ; t ; \\
t-\Delta t ; t-3 \Delta t ; t-6 \Delta t ; \\
t-12 \Delta t ; t-24 \Delta t\end{array}$ \\
& & $\begin{array}{l}t ; t-\Delta t ; t-3 \Delta t ; t-6 \Delta t ; \\
t-12 \Delta t ; t-24 \Delta t\end{array}$ \\
\hline$P$ & Heating power & \\
\hline
\end{tabular}

The Beta regression parameters were estimated by the maximum likelihood method. Furthermore, for each Beta strategy, a stepwise regression technique was used to find the retained explanatory variables set (see $\S 3.2 .1$ ). 


\subsubsection{Performance evaluation}

Objective criteria to evaluate the predictive quality of the Beta strategies were required. Therefore, their performance was assessed by means of the following indicators:

- the average heating power,

- the cumulative cost,

- the percentage of energy consumption which is load shifted during high peak hours, compared to $\mathrm{a} 19^{\circ} \mathrm{C}$ constant temperature setpoint strategy,

- the percentage of energy consumption which is load shifted during peak hours, compared to a $19^{\circ} \mathrm{C}$ constant temperature setpoint strategy,

- the thermal discomfort rates:

- $T I_{\text {min }}$ : period duration (in $\%$ ) when $T_{\text {zone }}(t) \leq T_{\min }$,

- $T I_{\text {max }}$ : period duration (in $\%$ ) when $T_{\text {zone }}(t) \geq T_{\max }$,

- number of times when the variation rate of the zone temperature (between two time steps) is above the maximum rate of variation $\left(N_{\text {var_max }}\right)$.

In order to assess the reliability of heuristic strategies, we used the mean bias error (MBE), between heating powers $P$ calculated by dynamic programming and Beta strategies.

\section{Results and discussion}

\subsection{Weather data}

To generate training and validation data, TMY Meteonorm (Remund et al. 2007) data from Chambery (France) were used. Thus, Beta strategies' results were adjusted to the long term average climatic conditions. 
With the first six weeks of the TMY weather data, the optimal strategy was calculated by the dynamic programming method (i.e. 42 days, which is also the duration of the optimisation period). The first four weeks of the optimised results (training data) were used to identify the Beta regression parameters and the remaining two weeks of the optimised results (validation data) were used to assess the reliability of the identified Beta strategies. Consequently, Beta strategies were specific to the identification period (winter season in our case). Meteorological features are summarised in Table 5.

Table 5. Weather data.

\begin{tabular}{|c|c|c|}
\hline & Training data & Validation data \\
\hline Minimal temperature $\left({ }^{\circ} \mathrm{C}\right)$ & -9.3 & -5.6 \\
\hline Average temperature $\left({ }^{\circ} \mathrm{C}\right)$ & 0.7 & 1.9 \\
\hline Maximal temperature $\left({ }^{\circ} \mathrm{C}\right)$ & 11.2 & 56 \\
\hline $\begin{array}{c}\text { Average global horizontal } \\
\text { irradiance }\left(\mathrm{W} . \mathrm{m}^{-2}\right)\end{array}$ & 45 & \\
\hline $\begin{array}{c}\text { Maximal global horizontal } \\
\text { irradiance }\left(\mathrm{W} . \mathrm{m}^{-2}\right)\end{array}$ & 425 & 472 \\
\hline
\end{tabular}

\subsection{Study of the influence of training data}

Five Beta regression strategies were identified and implemented in the building energy simulation tool COMFIE. Table 6 summarises Beta regression strategies' results obtained with the validation data (weeks 5 and 6). The dynamic programming reference results are described in the DP column. 
Table 6. Beta strategies' results obtained with validation data.

\begin{tabular}{|c|c|c|c|c|c|c|}
\hline & BETA_1 & BETA_2 & BETA_3 & BETA_4 & BETA_5 & DP \\
\hline $\begin{array}{c}\text { Average heating } \\
\text { power }(\mathrm{W})\end{array}$ & 1129 & 1975 & 835 & 1113 & 1058 & 792 \\
\hline $\begin{array}{c}\text { Cumulative cost } \\
(€)\end{array}$ & 42 & 72.9 & 24.2 & 35.5 & 30.7 & 23.7 \\
\hline $\begin{array}{l}\text { High peak hours } \\
\text { energy load } \\
\text { shifted }(\%)\end{array}$ & 13 & 100 & 100 & 100 & 100 & 100 \\
\hline $\begin{array}{l}\text { Peak hours } \\
\text { energy load } \\
\text { shifted }(\%)\end{array}$ & -9 & -468 & 100 & -15 & 100 & 74 \\
\hline$T I_{\min }(\%)$ & 0 & 0 & 3 & 0 & 0 & 0 \\
\hline$T I_{\max }(\%)$ & 6 & 93 & 0 & 18 & 7 & 0 \\
\hline$T_{\min } / T_{\max }\left({ }^{\circ} \mathrm{C}\right)$ & $\begin{array}{l}19.9 / \\
24.5\end{array}$ & $\begin{array}{l}21.4 / \\
31.3\end{array}$ & $\begin{array}{l}18.8 / \\
22.9\end{array}$ & $\begin{array}{l}19.9 / \\
24.4\end{array}$ & $\begin{array}{l}19.6 / \\
24.1\end{array}$ & $19 / 22.9$ \\
\hline$N_{\text {var_max }}$ & 1 & 11 & 9 & 2 & 3 & 0 \\
\hline $\operatorname{MBE}(\%)$ & -43 & -173 & -5 & -41 & -34 & - \\
\hline
\end{tabular}

BETA_1 and BETA_2 did not follow the dynamic programming's behaviour. For example, the BETA_2 strategy performed significantly worse than the dynamic programming, with a very high thermal discomfort rate $T I_{\max }(93 \%)$ and an indoor temperature exceeding $31^{\circ} \mathrm{C}$. Furthermore, its cumulative cost was three times higher than the dynamic programming's cumulative cost and its energy consumption during peak hours was more than four times higher ( $-468 \%$ of peak hours energy load shifted) than the energy consumed with a $19^{\circ} \mathrm{C}$ constant temperature setpoint strategy. BETA_1 
had a high cumulative cost ( $42 €)$, and a significant mean bias error (- $43 \%)$. Thus, BETA_1 and BETA_2 did not qualify as relevant strategies.

The results of BETA_4 and BETA_5 were also different from the optimised results. For instance, BETA_4 and BETA_5 had a significant cumulative cost $(35.5 €$ and $30.7 €$ respectively) and a high average heating power (1113 $\mathrm{W}$ and $1058 \mathrm{~W}$ respectively). Moreover, mean bias errors were very high ( $-41 \%$ and $-34 \%$ respectively). Thus, BETA_4 and BETA_5 did not qualify either as relevant controllers. Explanatory variables used by BETA_1, BETA_2, BETA_4 and BETA_5 are presented in Appendix A.

Figure 4 illustrates the interesting performance of BETA_3 which produced results similar to the reference's (DP). It used seven explanatory variables (including the intercept term of the regression analysis) which are listed in Table 7. Firstly, due to its design, no electricity was consumed during high peak hours and peak hours (which is better than DP). Secondly, it had a cumulative cost and an average heating power close to dynamic programming ( $24.2 €$ and $835 \mathrm{~W}$ compared to $23.7 €$ and $792 \mathrm{~W}$ for DP). Thirdly, its mean bias error (-5\%) was quite small compared with the other regressions. Fourthly, the indoor temperature variation was quite similar to DP's (Figure 5). Thus, BETA_3 presented a satisfactory behaviour and appeared as a possible candidate for a simplified control system. However, on some occasions, it did not respect the thermal comfort constraints. In fact, its thermal discomfort rate $T I_{\min }$ was equal to $3 \%$ with an average gap of $0.1{ }^{\circ} \mathrm{C}$. This means that, on average, the building was heated at $18.9^{\circ} \mathrm{C}$ (instead of $19^{\circ} \mathrm{C}$ ) for $3 \%$ of the time. Furthermore, the maximal rate of variation of the zone temperature was violated 9 times. However, this constraint violation appeared each time at 9 a.m. (transitional period between off-peak hours and high peak hours), when 
occupants were mostly absent. Consequently, this was an acceptable violation of the maximal rate of temperature variation.

Although the minimal temperature constraint infringement could be acceptable, to improve BETA_3's behaviour and to prevent further discrepancy, a back-up controller that switched heating on as soon as the indoor temperature was below $19^{\circ} \mathrm{C}$ was implemented.

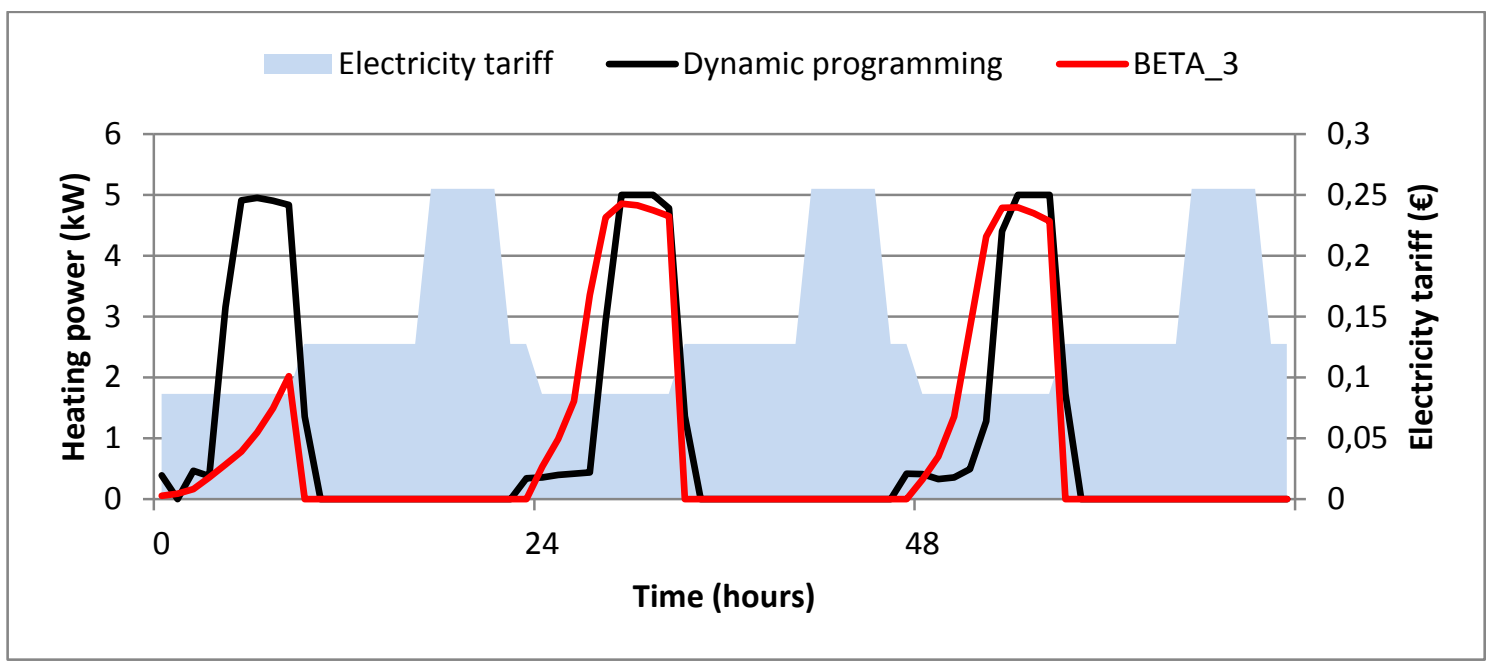

Figure 4. Heating power calculated by dynamic programming and BETA_3 (first three days of the sixth week).

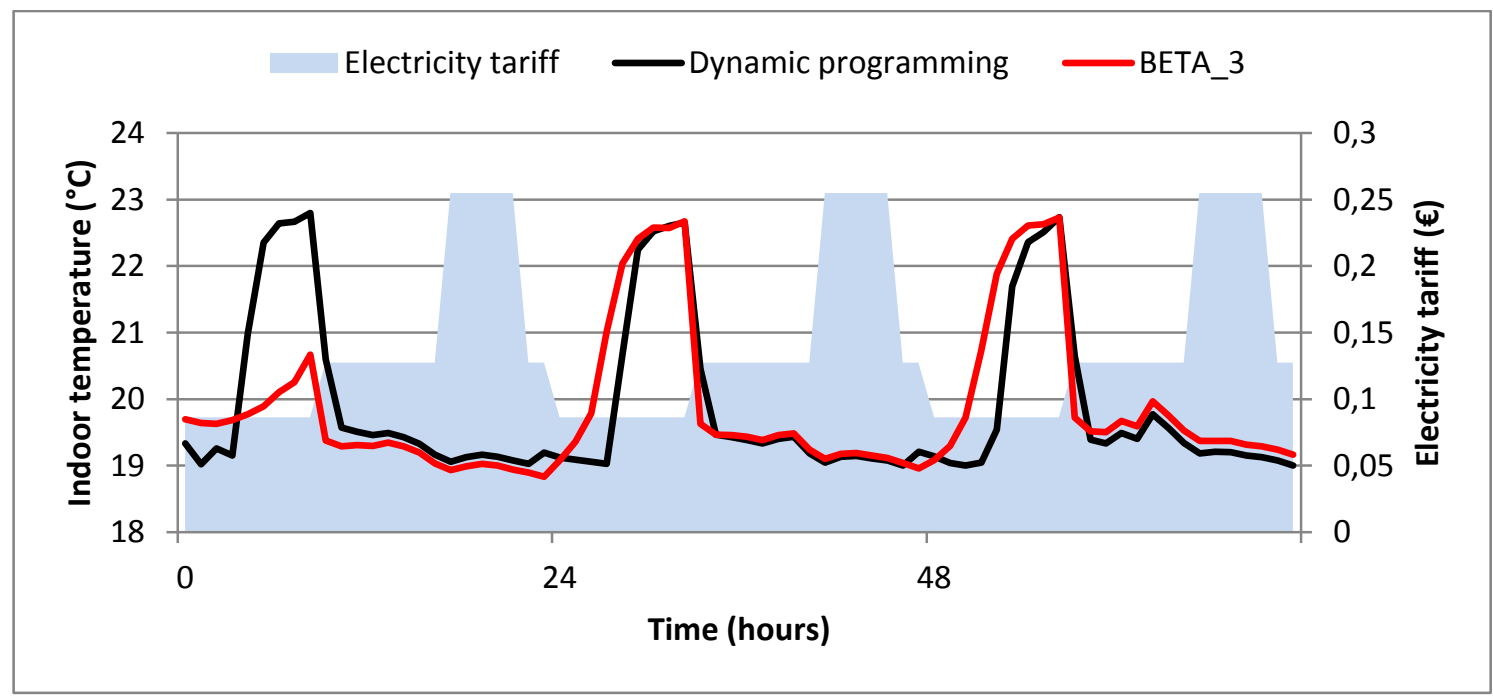


Figure 5. Evolution of indoor temperature corresponding to the dynamic programming and BETA_3 control strategies (first three days of the sixth week).

Table 7. BETA_3 regression model.

\begin{tabular}{|c|c|}
\hline Retained explanatory variable & Estimated regression parameter \\
\hline Intercept & $4.21 \mathrm{e}+01$ \\
\hline$T_{\text {out }}(t+6 \Delta t)$ & $-4.79 \mathrm{e}-02$ \\
\hline$G_{h}(t+6 \Delta t)$ & $-2.70 \mathrm{e}-04$ \\
\hline$T_{\text {zone }}(\mathrm{t})$ & $-1.58 \mathrm{e}+00$ \\
\hline$T_{\text {zone }}(t-\Delta t)$ & $-5.26 \mathrm{e}-01$ \\
\hline $\mathrm{P}(t)$ & $2.42 \mathrm{e}-03$ \\
\hline$H_{\text {gains }}(\mathrm{t}-3 \Delta t)$ & $-9.69 \mathrm{e}-03$ \\
\hline
\end{tabular}

\subsection{Back-up controller}

An ideal on-off controller was applied during peak and high peak hours as BETA_3 did not work during these periods. Its control law switched between the minimum heating power $P_{\min }(0 \mathrm{~W})$ and the maximum heating power $P_{\max }(5000 \mathrm{~W})$. The ideal on-off controller was switched on when the indoor temperature fell below $19^{\circ} \mathrm{C}$ and was switched off when the indoor temperature rose above $19^{\circ} \mathrm{C}+\varepsilon$ (in order to respect the $19^{\circ} \mathrm{C}$ temperature setpoint). Assuming that $\varepsilon$ tends toward 0 , the deadband of the on-off controller tends toward 0 . Thus, this controller calculated the exact heating power $P_{\text {ideal }}$ to reach $19^{\circ} \mathrm{C}$. In practice, the BETA_3 strategy calculated the heating power $P(t+\Delta t)$ every hour whereas the controller ran over a much shorter time step. Thus, the numerical simulation of this ideal on-off controller aimed at assessing the maximal theoretical performance of BETA_3 + back-up controller. The control law was the following: 
- During off peak hours

$$
P(t+\Delta t)=\left\{\begin{array}{cl}
B E T A_{-} 3 & T_{\text {zone }}(t) \leq T_{\max } \\
0 & T_{\text {zone }}(t)>T_{\max }
\end{array}\right.
$$

- During peak and high peak hours

$$
P(t+\Delta t)=\left\{\begin{array}{ccc}
P_{\text {ideal }} & \text { if } & T_{\text {zone }}(t) \leq 19^{\circ} \mathrm{C} \\
0 & \text { if } & T_{\text {zone }}(t) \geq 19^{\circ} \mathrm{C}+\varepsilon
\end{array} \quad \varepsilon \rightarrow 0\right.
$$

The results are shown in Table 8. Firstly, thanks to the back-up controller, the BETA_3 strategy respected temperature constraints (the lowest temperature was $19^{\circ} \mathrm{C}$ ).

Secondly, adding a back-up controller led to a small decrease of the BETA_3 strategy's performances. Associated with the BETA_3 strategy, it allowed $99 \%$ of high peak hours to be load-shifted in comparison with the $100 \%$ obtained by the BETA_3 strategy and the dynamic programming. Similarly, it allowed $99 \%$ of peak hours to be load shifted in comparison with the figures obtained by the BETA_3 strategy and dynamic programming (100\% and $74 \%$ respectively). Thus, a negligible deterioration of peak and high peak hours load shifted were observed. The average heating power used during peak and high peak hours which were not shifted was low (123 W and $60 \mathrm{~W}$ respectively). Finally, the BETA_3 + back-up controller resulted in a cumulative cost $(24.3 €)$ and an average heating power $(836 \mathrm{~W})$ very close to BETA_3 and dynamic programming. 
Table 8. BETA_3 + back-up controller results on validation data.

\begin{tabular}{|c|c|c|c|}
\hline & BETA_3 & $\begin{array}{l}\text { BETA_3 + back- } \\
\text { up controller }\end{array}$ & DP \\
\hline Average heating power (W) & 835 & 836 & 792 \\
\hline Cumulative cost $(€)$ & 24.2 & 24.3 & 23.7 \\
\hline $\begin{array}{l}\text { High peak hours energy } \\
\text { load shifted }(\%)\end{array}$ & 100 & 99 & 100 \\
\hline $\begin{array}{c}\text { Peak hours load energy } \\
\text { shifted (\%) }\end{array}$ & 100 & 99 & 74 \\
\hline$T I_{\min }(\%)$ & 3 & 0 & 0 \\
\hline$T I_{\max }(\%)$ & 0 & 0 & 0 \\
\hline$T_{\min } / T_{\max }\left({ }^{\circ} \mathrm{C}\right)$ & $18.8 / 22.9$ & $19 / 22.9$ & $19 / 22.9$ \\
\hline$N_{\text {var_max }}$ & 9 & 9 & 0 \\
\hline $\operatorname{MBE}(\%)$ & -5 & -6 & - \\
\hline
\end{tabular}

Consequently, adding an on-off controller to BETA_3 enabled to improve BETA_3's behaviour and to respect temperature constraints with a negligible deterioration of performance. Figure 6 shows the BETA_3's behaviour both with and without the on-off controller. Thus, BETA_3 + back-up controller had a satisfactory behaviour. To validate its behaviour, it is interesting to compare its results with a purely heuristic control strategy. 


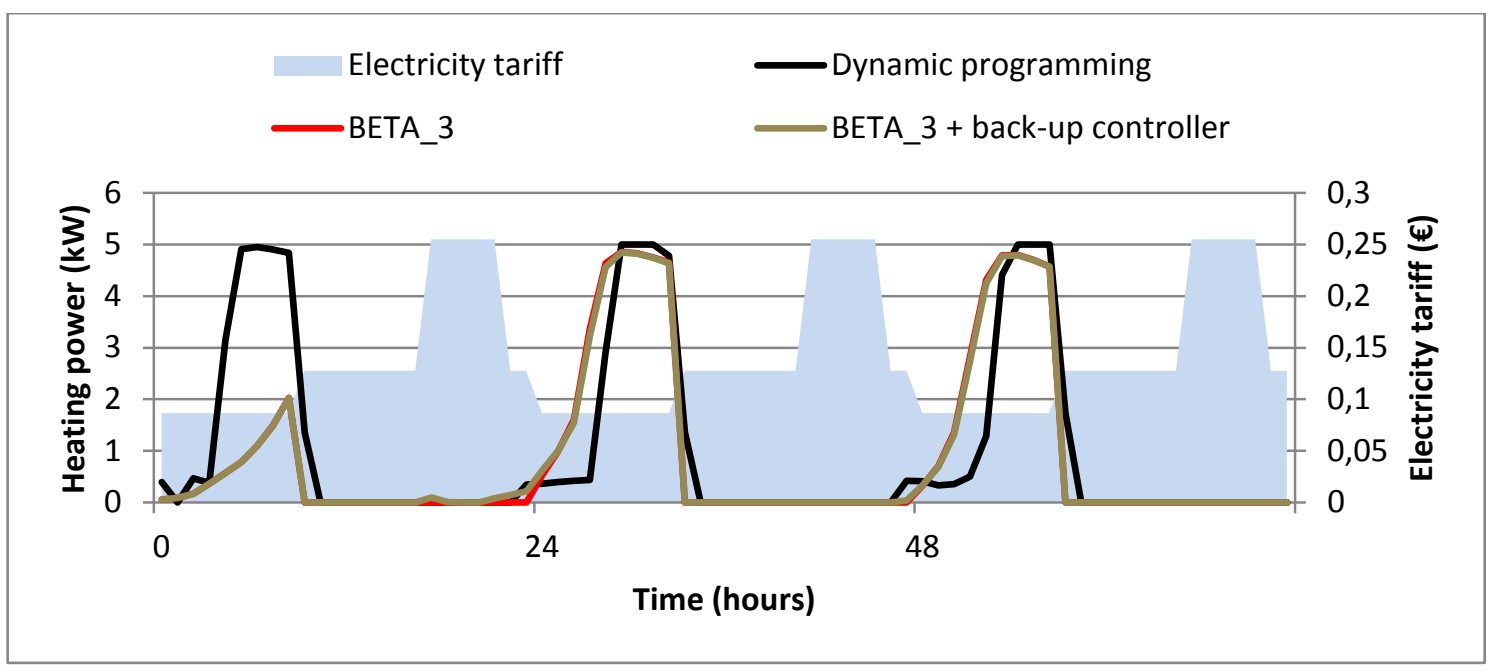

Figure 6. Heating power calculated by dynamic programming, BETA_3 and BETA_3 + back-up controller (first three days of the sixth week).

\subsection{Comparison with a simple heuristic law}

A significant effort is required to develop the BETA_3 + back-up controller strategy for a given site. Consequently, it is very useful to compare results with a purely heuristic control strategy in order to evaluate its benefits. The heuristic law was designed such that maximal load shifting was guaranteed:

- During off peak hours, maintain the indoor temperature at the upper comfort $\operatorname{limit} T_{\max }$

- During peak hours and high peak hours, use the lower comfort limit $T_{\min }$ as the set point.

The results of this strategy are shown in Table 9. No electricity was consumed during high peak hours and peak hours with the purely heuristic strategy. However, this heuristic strategy had a higher cumulative cost than BETA_3 + back-up controller strategy ( $36.5 €$ and $24.3 €$ respectively), and average heating power (1258 W and $836 \mathrm{~W}$ respectively). Finally, the mean bias of the heuristic strategy appeared large in comparison with the BETA_3 + back-up controller strategy's error (-59 \% and -6 \% 
respectively).

Table 9. Heuristic law results on validation data.

\begin{tabular}{|c|c|c|c|}
\hline & $\begin{array}{c}\text { BETA_3 + back- } \\
\text { up controller }\end{array}$ & Heuristic law & DP \\
\hline Average heating power (W) & 836 & 1258 & 792 \\
\hline Cumulative cost $(€)$ & 24.3 & 36.5 & 23.7 \\
\hline $\begin{array}{l}\text { High peak hours energy } \\
\text { load shifted }(\%)\end{array}$ & 99 & 100 & 100 \\
\hline $\begin{array}{c}\text { Peak hours energy load } \\
\text { shifted }(\%)\end{array}$ & 99 & 100 & 74 \\
\hline$T I_{\min }(\%)$ & 0 & 0 & 0 \\
\hline$T I_{\max }(\%)$ & 0 & 1 & 0 \\
\hline$T_{\min } / T_{\max }\left({ }^{\circ} \mathrm{C}\right)$ & $19 / 22.9$ & $19.7 / 24.3$ & $19 / 22.9$ \\
\hline$N_{\text {var_max }}$ & 9 & 11 & 0 \\
\hline $\operatorname{MBE}(\%)$ & -6 & -59 & - \\
\hline
\end{tabular}

Figures 7 and 8 show the behaviours of the purely heuristic control strategy, the BETA_3 + back-up controller strategy and the dynamic programming method. From these simulations, it appears that the BETA_3 + back-up controller strategy had a better performance than the purely heuristic control strategy. For instance, the heating power calculated by the heuristic control strategy and the resulting evolution of indoor temperature were quite different from the BETA_3 + back-up controller and dynamic programming results. 


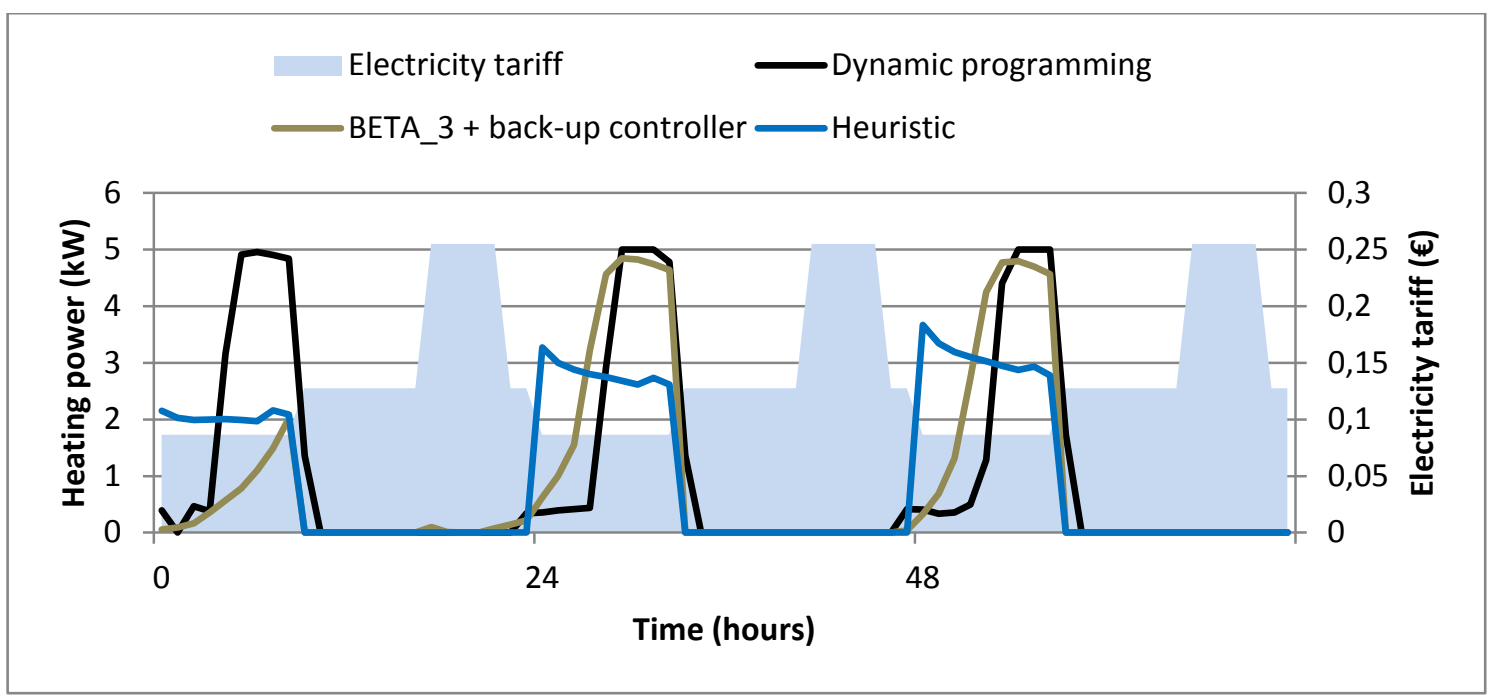

Figure 7. Heating power calculated by dynamic programming, BETA_3 + back-up controller and Heuristic law (first three days of the sixth week).

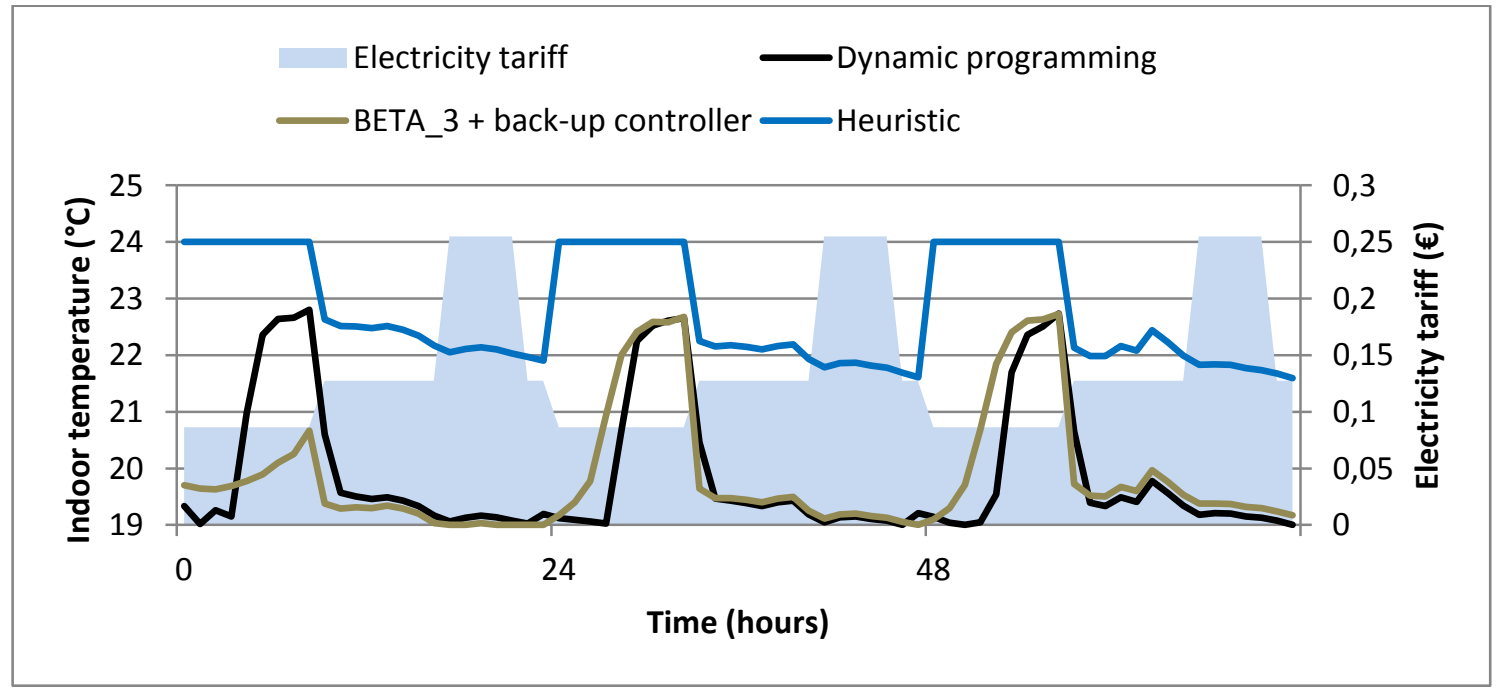

Figure 8. Indoor temperature evolutions corresponding to the dynamic programming, BETA_3 + back-up controller and heuristic control strategies (first three days of the sixth week).

\subsection{Robustness to weather forecasting errors}

A robustness analysis was performed to assess the reliability of the rule-based approach. The goal was to evaluate the impact of weather forecasting errors on the 
BETA_3 + back-up controller's behaviour and to test the approximation accuracy of the identified heating control rule in real conditions.

\subsubsection{Weather data}

Local weather conditions data measured at Chambéry (FR) airport, which is 300 metres away from the building, were used to assess the approximation accuracy of the BETA_3 + back-up controller strategy (the simplified heating control rule identified at the $\S 4.3$ ) in real conditions. This local weather data corresponded to measurements from January 15th to February 14th, 2012 (31 days). Meteorological features are summarised in Table 10.

Table 10. Weather data.

\begin{tabular}{|c|c|}
\hline Minimal temperature $\left({ }^{\circ} \mathrm{C}\right)$ & -14 \\
\hline Average temperature $\left({ }^{\circ} \mathrm{C}\right)$ & -0.22 \\
\hline Maximal temperature $\left({ }^{\circ} \mathrm{C}\right)$ & 11.33 \\
\hline $\begin{array}{c}\text { Average global horizontal } \\
\text { irradiance }\left(\mathrm{W} . \mathrm{m}^{-2}\right)\end{array}$ & 60 \\
\hline $\begin{array}{c}\text { Maximal global horizontal } \\
\text { irradiance }\left(\mathrm{W} . \mathrm{m}^{-2}\right)\end{array}$ & 569 \\
\hline
\end{tabular}

\subsubsection{Sensitivity assessment}

A simplified procedure was implemented to assess the impact of weather forecasting errors on the heating power calculated by the BETA_3 + back-up controller strategy. The goal was to get a rough estimate of the sensitivity of the heating power calculated by the simplified heating control rule.

The sensitivity assessment was conducted in three steps. Firstly, lower and upper bounds were associated with the explanatory variables related to weather forecast 
(Table 11). Theses bounds were deliberately chosen large in order to assess the robustness of the identified heating control rule to a significant weather forecasting error. Secondly, in order to estimate the upper bound of the heating power calculated by the strategy, we considered the upper or lower uncertainty bounds of each explanatory variable depending on the sign of the associated regression parameter. Thirdly, the same procedure was applied to estimate the lower bound of the heating power calculated by the strategy. This sensitivity assessment enabled to place the BETA_3 + back-up controller strategy in an unfavourable case concerning forecasting errors.

Table 11. Upper and lower bounds of the explanatory variables.

\begin{tabular}{|c|c|c|c|}
\hline $\begin{array}{c}\text { Explanatory } \\
\text { variable }\end{array}$ & $\begin{array}{c}\text { Sign of the associated } \\
\text { regression parameter }\end{array}$ & $\begin{array}{c}\text { Overestimation of } \\
\text { the heating power }\end{array}$ & $\begin{array}{c}\text { Underestimation of } \\
\text { the heating power }\end{array}$ \\
\hline$T_{\text {out }}(t+6 \Delta t)$ & - & True value $-3^{\circ} \mathrm{C}$ & True value $+3^{\circ} \mathrm{C}$ \\
\hline$G_{h}(t+6 \Delta t)$ & - & True value $-40 \%$ & True value $+40 \%$ \\
\hline
\end{tabular}

\subsubsection{Results}

In Table 12, we can observe the identified heating control rule had good robustness properties to weather forecasting errors. For example, when the heating power was underestimated, the average heating power $(991 \mathrm{~W})$ decreased which means less heat stored in the house. Consequently, electricity consumption load shifted during high peak hours and peak hours was slightly reduced (96\% and $97 \%$ respectively). The observation is reversed when the heating power was overestimated. The increase in the average heating power $(1006 \mathrm{~W})$ resulted in increased high peak hours load shifted (99\%). In both cases, we can observe a small cumulative cost change.

Figure 9 shows the behaviour of the BETA_3 + back-up controller strategy relatively to weather forecasting errors. The heating powers calculated by the strategy were quite 
similar in the three cases. Indoor temperature variations are presented in Figure 10. As expected, when the heating power was overestimated, temperature variations were slightly higher. The reverse was observed when the heating power was underestimated. However, these differences were quite small relatively to heating strategy calculated by the BETA_3 + back-up controller strategy with perfect weather forecast. From these results, it appears that the BETA_3 + back-up controller was robust to weather forecasting errors and consequently presented a satisfactory behaviour.

Table 12. Sensitivity assessment results.

\begin{tabular}{|c|c|c|c|c|}
\hline & $\begin{array}{l}\text { BETA_3 + } \\
\text { back-up } \\
\text { controller }\end{array}$ & $\begin{array}{c}\text { BETA_3+ } \\
\text { back-up } \\
\text { controller } \\
\text { (overestimation) }\end{array}$ & $\begin{array}{l}\text { BETA_3 + back- } \\
\text { up controller } \\
\text { (underestimation) }\end{array}$ & DP \\
\hline $\begin{array}{l}\text { Average heating power } \\
\text { (W) }\end{array}$ & 998 & 1006 & 991 & 941 \\
\hline Cumulative cost ( $€$ ) & 64.9 & 65.1 & 64.9 & 62.2 \\
\hline $\begin{array}{c}\text { High peak hours } \\
\text { energy load shifted }(\%)\end{array}$ & 98 & 99 & 96 & 100 \\
\hline $\begin{array}{c}\text { Peak hours load energy } \\
\text { shifted }(\%)\end{array}$ & 98 & 98 & 97 & 80 \\
\hline$T I_{\min }(\%)$ & 0 & 0 & 0 & 0 \\
\hline$T I_{\max }(\%)$ & 0 & 0 & 0 & 0 \\
\hline$T_{\min } / T_{\max }\left({ }^{\circ} \mathrm{C}\right)$ & $19 / 22.9$ & $19 / 23$ & $19 / 22.9$ & $19 / 23.2$ \\
\hline$N_{\text {var_max }}$ & 27 & 27 & 27 & 0 \\
\hline $\operatorname{MBE}(\%)$ & -6 & -7 & -5 & - \\
\hline
\end{tabular}




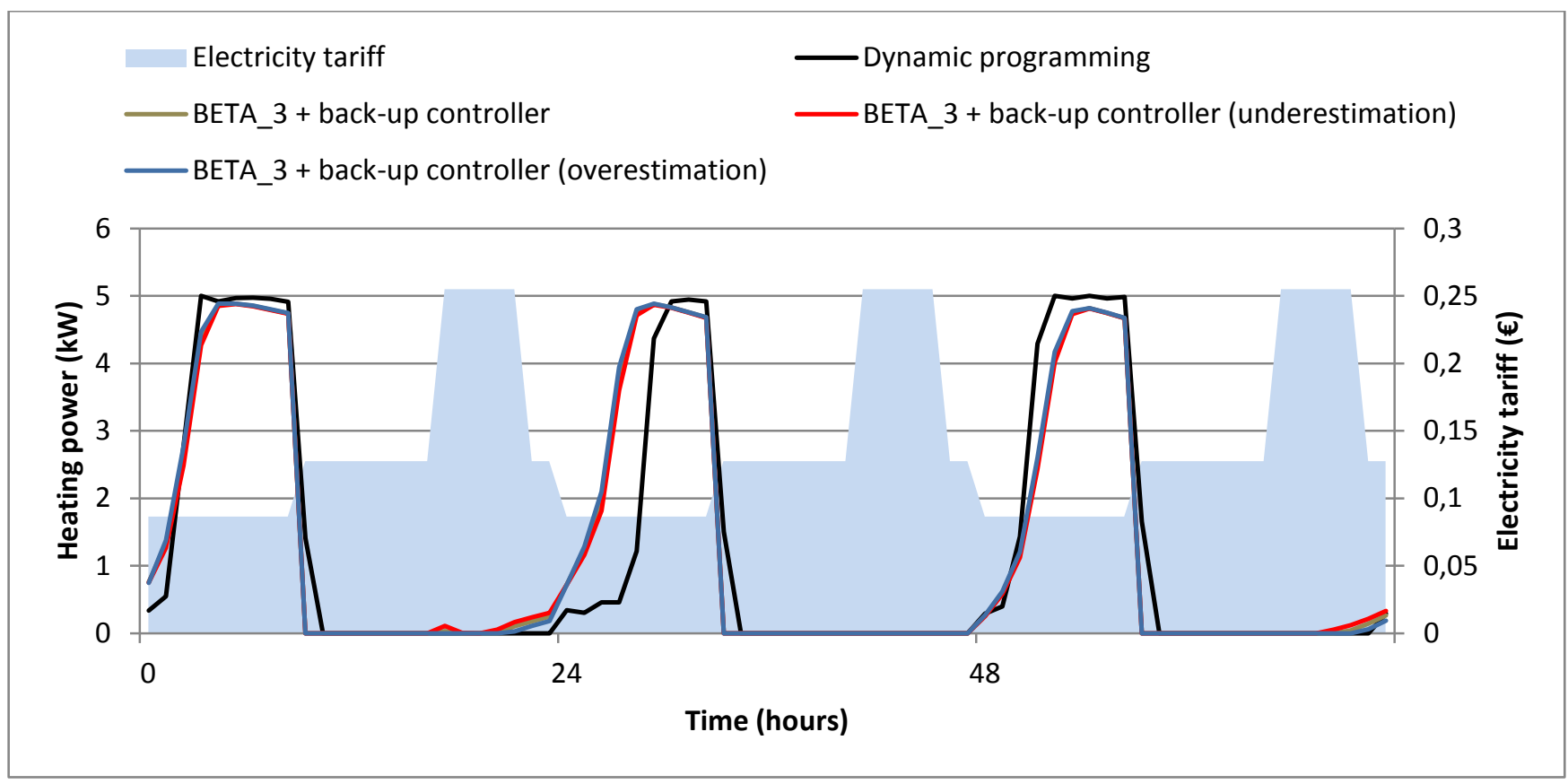

Figure 9. Heating power under weather forecasting errors (measured data, February $10^{\text {th }}$ to $12^{\text {th }}, 2012$ ). 


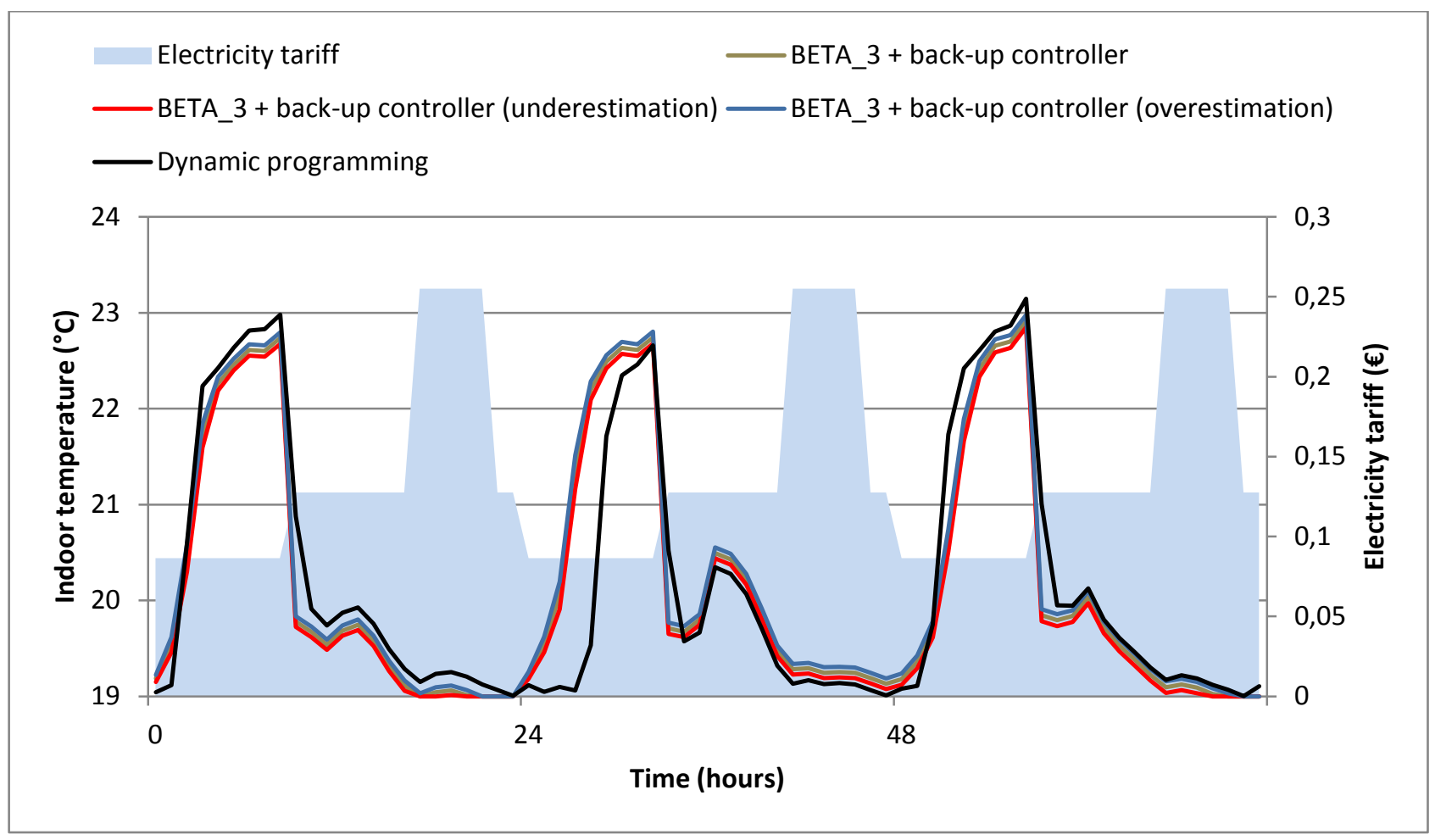

Figure 10. Indoor temperature variations under weather forecasting errors (measured data, February $10^{\text {th }}$ to $12^{\text {th }}, 2012$ ).

\section{Conclusion}

Dynamic programming was used to study load shifting of heating systems in an energy efficient building. In order to reduce computational effort, a statistical technique (Beta regression) that yields near-optimal heating control laws from the dynamic programming results was investigated. With this method a relationship between explanatory variables and a response variable is expressed through a regression structure. First of all, the results showed that Beta regression strategies were able to mimic the general characteristics of the dynamic programming results, with a much smaller computing time (150 times faster than the dynamic programming method) and a slight constraints infringement. Moreover, to improve the Beta regression strategy's behaviour, an on-off controller was added that switched heating on as soon as the indoor temperature reached the lower constraint. The results show that the Beta regression 
strategy with such an on-off controller respected temperature constraints with a slight deterioration of peak hours and high peak hours load shifting. In order to validate the benefits of the use of Beta regression strategies, it was compared with a purely heuristic control strategy. However, the heuristic law was rather crude and could be improved by observing the dynamic programming results. Finally, a simplified sensitivity assessment showed the Beta regression strategy's robustness to weather forecast error. Therefore, rule extraction is a promising technique to develop operational control strategies. Given their simple mathematical formulation, Beta regression strategies could be implemented in real-time building control systems.

Despite the good results shown in this simulation study, the effectiveness of the proposed approach remains to be shown in real buildings. In particular, the Beta regression strategy's robustness to measurement uncertainty of explanatory variables should be investigated. Furthermore, an open question is the transferability of the rules derived upon the model of the building. It could be interesting to identify the Beta regression strategies on different building types and to compare the obtained rules. The Beta regression strategies' sensitivity to a slight change in the optimisation problem (e.g. tariff electricity change) could also be analysed. Finally, amongst possible perspectives, the method could be extended to multi-zone building models but this would require to take into account the interaction between several zones of the buildings and consequently to define specific explanatory variables.

\section{Acknowledgment}

This work was supported by the French Research National Agency (ANR) through the PRECCISION project (ANR-12-VDBU-0006), part of "Villes et Bâtiments Durables (VBD) 2012” program. 


\section{Nomenclature}

\subsection{Latin}

$b_{j} \quad$ beta regression

parameters

$C_{\text {elec }} \quad$ electricity price [€]

$G_{h} \quad$ global horizontal

radiation $\left[\mathrm{W} . \mathrm{m}^{-2}\right]$

$g($.$) \quad link function$

$H_{\text {gains }} \quad$ Internal heat gains

$N \quad$ number of time steps

$N_{\text {var_max }} \quad$ number of times when

the variation rate of $T_{z o n e}$

is above the maximal rate

of variation

$P \quad$ heating power [W]

$P^{\prime} \quad$ normalised heating

power

$P^{\prime \prime} \quad$ transformation of $P^{\prime}$

$P_{\text {BETA_ } i \quad \text { heating power predicted }}$

by the $i^{\text {th }}$ Beta strategy

[W]

$P_{\text {ideal }} \quad$ heating power to reach

the temperature setpoint

[W]
Solar Factor (glazing

transmittance) [-]

$T_{\max } \quad$ Maximal acceptable

temperature in heating

zones $\left[{ }^{\circ} \mathrm{C}\right]$

$T_{\min } \quad$ Minimal acceptable

temperature in heating

zones $\left[{ }^{\circ} \mathrm{C}\right]$

$T_{\text {out }}$

$T_{\text {zone }}$

$T I_{\max }$

$T I_{\min }$

outdoor temperature $\left[{ }^{\circ} \mathrm{C}\right]$

zone temperature $\left[{ }^{\circ} \mathrm{C}\right]$

high thermal discomfort

rate $[\%]$

low thermal discomfort

rate $[\%]$

time $[\mathrm{s}]$

$t_{f}$

duration of the

optimisation period

[hours]

$U_{g w} \quad$ window overall heat

transfer coefficient

$\left[\mathrm{W} \cdot \mathrm{m}^{-2} \cdot \mathrm{K}^{-1}\right]$

$x_{j}$

explanatory variables

$y$

output variable 
7.2 Greek

$\Delta t$

$\varepsilon$

$\Phi$

\subsection{Abbreviations}

DP

Dynamic Programming

$\max$

$\min$

time step

controller's dead band

$\left[{ }^{\circ} \mathrm{C}\right]$

standard normal

distribution function

Maximal

Minimal

\section{Appendix A}

Tables A1 and A2 list the explanatory variables used by the BETA_1, BETA_2, BETA_4 and BETA_5 strategies.
Mean Bias Error

MPC

Model Predictive Control

$\mathrm{TD}_{\mathrm{HPH}} \quad$ High peak hours training

data

$\mathrm{TD}_{\mathrm{OPH}} \quad$ Off-peak hours training

data

$\mathrm{TD}_{\mathrm{PH}} \quad$ Peak hours training data

TMY

Typical Meteorological

Year 
Table A1. BETA_1, BETA_4 and BETA_5 explanatory variables.

\begin{tabular}{|c|c|}
\hline Retained explanatory variable & Estimated regression parameter \\
\hline Intercept & $4.29 \mathrm{e}+01$ \\
\hline$T_{\text {out }}(t+\Delta t)$ & $-5.39 \mathrm{e}-02$ \\
\hline$G_{h}(t+6 \Delta t)$ & $-3.95 e-04$ \\
\hline$C_{\text {elec }}(t+\Delta t)$ & $-2.36 e-01$ \\
\hline$C_{\text {elec }}(t+6 \Delta t)$ & $-9.90 e-02$ \\
\hline$T_{\text {zone }}(\mathrm{t})$ & $-1.24 \mathrm{e}+00$ \\
\hline$T_{\text {zone }}(t-3 \Delta t)$ & $-1.33 \mathrm{e}-01$ \\
\hline$T_{\text {zone }}(t-12 \Delta t)$ & $-5.35 e-01$ \\
\hline $\mathrm{P}(t)$ & $1.70 \mathrm{e}-03$ \\
\hline $\mathrm{P}(t-12 \Delta t)$ & $4.54 \mathrm{e}-04$ \\
\hline$H_{\text {gains }}(\mathrm{t}-\Delta t)$ & $-5.81 e-03$ \\
\hline$H_{\text {gains }}(\mathrm{t}-3 \Delta t)$ & $-2.63 e-03$ \\
\hline$H_{\text {gains }}(\mathrm{t}-12 \Delta t)$ & $-6.02 e-03$ \\
\hline$H_{\text {gains }}(\mathrm{t}+3 \Delta t)$ & $-3.15 e-03$ \\
\hline
\end{tabular}


Table A2. BETA_2 explanatory variables.

\begin{tabular}{|c|c|}
\hline Retained explanatory variable & Estimated regression parameter \\
\hline Intercept & $1.96 \mathrm{e}+01$ \\
\hline$T_{\text {out }}(t+\Delta t)$ & $-1.05 \mathrm{e}-01$ \\
\hline$G_{h}(t+6 \Delta t)$ & $-3.66 \mathrm{e}-04$ \\
\hline$C_{\text {elec }}(t+\Delta t)$ & $-1.25 \mathrm{e}+00$ \\
\hline$C_{\text {elec }}(t+3 \Delta t)$ & $6.13 \mathrm{e}-02$ \\
\hline$T_{\text {zone }}(\mathrm{t}-6 \Delta t)$ & $-2.22 \mathrm{e}-01$ \\
\hline$T_{\text {zone }}(t-12 \Delta t)$ & $-4.24 \mathrm{e}-01$ \\
\hline $\mathrm{P}(t)$ & $1.07 \mathrm{e}-03$ \\
\hline$H_{\text {gains }}(\mathrm{t}-3 \Delta t)$ & $-8.51 \mathrm{e}-03$ \\
\hline
\end{tabular}

\section{References}

ADEME. 2012. "Les chiffres clé du bâtiment - Energie Environnement". Agence de l'Environnement de la Maîtrise de l'Energie (ADEME). http://multimedia.ademe.fr/catalogues/chiffres-cles-batiment-2012/.

ASHRAE. 2004. "Standard 55-2004, Thermal Environmental Conditions for Human Occupancy". American Society of Heating, Refrigerating and Air-Conditioning Engineers. Atlanta, GA, USA.

Bellman, R. 1957. Dynamic programming. Princeton University Press.

Brun, A., C. Spitz and E. Wurtz. 2009. “Analyse du comportement de différents codes de calcul dans le cas de bâtiments à haute efficacité énergétique”. IXème Colloque Interuniversitaire Franco-Québécois sur la Thermique des Systèmes, , Lille, France, May 18-20.

Coffey, B. 2013. “Approximating model predictive control with existing building simulation tools and offline optimization”. Journal of Building Performance Simulation 6 (3): 220-35. doi:10.1080/19401493.2012.737834. 
Corbin, C. D., G. P. Henze, and P. May-Ostendorp. 2013. "A model predictive control optimization environment for real-time commercial building application". Journal of Building Performance Simulation 6 (3): 159-74. doi:10.1080/19401493.2011.648343.

Domahidi, A., F. Ullmann, M. Morari, and C. N. Jones. 2014. "Learning decision rules for energy efficient building control". Journal of Process Control, Energy Efficient Buildings Special Issue, 24 (6): 763-72. doi:10.1016/j.jprocont.2014.01.006.

Favre, B., and B. Peuportier. 2014. "Application of dynamic programming to study load shifting in buildings". Energy and Buildings 82: 57-64. doi:10.1016/j.enbuild.2014.07.018.

Ferrari, S., and F. Cribari-Neto. 2004. "Beta Regression for Modelling Rates and Proportions". Journal of Applied Statistics 31 (7): 799-815. doi:10.1080/0266476042000214501.

Freire, R. Z., G. H. C. Oliveira, and N. Mendes. 2008. "Predictive controllers for thermal comfort optimization and energy savings". Energy and Buildings 40 (7): 1353-65. doi:10.1016/j.enbuild.2007.12.007.

Greensfelder, E. M., G. P. Henze, and C. Felsmann. 2011. “An investigation of optimal control of passive building thermal storage with real time pricing”. Journal of Building Performance Simulation 4 (2): 91-104. doi:10.1080/19401493.2010.494735.

Hämäläinen, R. P., J. Mäntysaari, J. Ruusunen, and P.-O. Pineau. 2000. “Cooperative consumers in a deregulated electricity market — dynamic consumption strategies and price coordination”. Energy 25 (9): 857-75. doi:10.1016/S03605442(00)00024-4.

Henze, G. P., D. E. Kalz, S. Lui, and C. Felsmann. 2005. "Experimental Analysis of Model-Based Predictive Optimal Control for Active and Passive Building Thermal Storage Inventory". HVAC\&R Research 11 (2): 189-213. doi:10.1080/10789669.2005.10391134.

Kelly, N., J. Hong, I. Richardson, and M. Thomson. 2011. "The influence of thermal storage on microgeneration flexibility”. In: Proceedings of the 2 nd International Conference in Microgeneration Technologies, Glasgow, Scotland, April 04-06. 
Le, K., R. Bourdais, and H. Guéguen. 2014. "From hybrid model predictive control to logical control for shading system: A support vector machine approach”. Energy and Buildings 84 : 352-59. doi:10.1016/j.enbuild.2014.07.084.

Mathews, E. H., D. C. Arndt, C. B. Piani, and E. van Heerden. 2000. "Developing cost efficient control strategies to ensure optimal energy use and sufficient indoor comfort”. Applied Energy 66 (2): 135-59. doi:10.1016/S0306-2619(99)00035-5.

May-Ostendorp, P. T., G. P. Henze, B. Rajagopalan, and C. D. Corbin. 2013.

"Extraction of supervisory building control rules from model predictive control of windows in a mixed mode building". Journal of Building Performance Simulation 6 (3): 199-219. doi:10.1080/19401493.2012.665481.

Moroşan, P.-D., R. Bourdais, D. Dumur, and J. Buisson. 2010. "Building temperature regulation using a distributed model predictive control". Energy and Buildings 42 (9): 1445-52. doi:10.1016/j.enbuild.2010.03.014.

Munaretto, F. , B. Peuportier and A. Guiavarch. 2013. "Accounting for thermal mass in thermal simulation tools: comparison of several assumptions". In: Proceedings of BS 2013: 13th Conference of International Building Performance Simulation Association. Chambéry, France, August 26-28.

Nygard Ferguson, A. M. 1990. "Predictive thermal control of building systems". PhD diss., École Polytechnique Fédérale de Lausanne.

Oldewurtel, F., A. Parisio, C. N. Jones, D. Gyalistras, M. Gwerder, V. Stauch, B. Lehmann, and M. Morari. 2012. "Use of model predictive control and weather forecasts for energy efficient building climate control". Energy and Buildings 45 (2): 15-27. doi:10.1016/j.enbuild.2011.09.022.

Peuportier, B. 2005. "Bancs d'essais de logiciels de simulation thermique”. Journée SFT-IBPSA "Outils de simulation thermoaéraulique du bâtiment". La Rochelle, France, march 31.

Peuportier, B., and I. Blanc-Sommereux. 1990. "Simulation tool with its expert interface for the thermal design of multizone buildings". International Journal of Sustainable Energy 8 (2): 109-20. doi:10.1080/01425919008909714.

Pineau, P. O., and R. P. Hämäläinen. 2010. "A perspective on the restructuring of the Finnish electricity market”. Energy Policy 28 (3): 181-92. 
Recht, T., F. Munaretto, P. Schalbart, and B. Peuportier. 2014. "Analyse de la fiabilité de COMFIE par comparaison à des mesures. Application à un bâtiment passif”' In: Proceedings IBPSA France 2014. Arras, France, May 20-21.

Remund, J., S. Kunz, and C. Schilter. 2007. "Handbook of METEONORM version 6.0, Part II: theory”. Meteotest, Fabrikstrasse 14, 3012 Bern, Switzerland. Www.meteonorm.com.

Robillart, M., P. Schalbart, and B. Peuportier. 2014. "Extraction of heating control rules from the dynamic programming method for load shifting in energy-efficient building”. In: Proceedings of the 9th International Conference on System Simulation in Buildings (SSB2014). Liege, Belgium, December 10-12.

Schmid, M., F. Wickler, K. O. Maloney, R. Mitchell, N. Fenske, and A. Mayr. 2013. “Boosted Beta Regression”. PLOS ONE 8 (4): e61623. doi:10.1371/journal.pone.0061623.

Smithson, M., and J. Verkuilen. 2006. "A Better Lemon Squeezer? MaximumLikelihood Regression with Beta-Distributed Dependent Variables”. Psychological Methods 11 (1): 54-71. doi:10.1037/1082-989X.11.1.54

Touretzky, C. R., and M. Baldea. 2014. "Integrating Scheduling and Control for Economic MPC of Buildings with Energy Storage". Journal of Process Control 24 (8): 1292-1300. doi:10.1016/j.jprocont.2014.04.015.

Vorger, E., P. Schalbart, and B. Peuportier. 2014. "Integration of a Comprehensive Stochastic Model of Occupancy in Buildings Simulation to Study How Inhabitants Influence Energy Performance". In: Proceedings PLEA 2014. Ahmedabad, India, December 16-18.

Wei, C. C., and N. S. Hsu. 2009. "Optimal tree-based release rules for real-time flood control operations on a multipurpose multireservoir system". Journal of Hydrology 365 (3-4): 213-24. doi:10.1016/j.jhydrol.2008.11.038.

Wilks, D. S.. 1995. "Statistical methods in the atmospheric sciences". San Diego, CA: Academic Press.

Wyse, B. 2011. "Investigation into the Time-Shifting of Domestic Heat Loads". MSc diss., University of Strathclyde. 